\title{
Genetic polymorphism of cytochrome P450 (CYP) 1A1, CYP1A2, and CYP2E1 genes modulate susceptibility to gastric cancer in patients with Helicobacter pylori infection
}

\author{
Ujjala Ghoshal $\cdot$ Shweta Tripathi $\cdot$ Sushil Kumar • \\ Balraj Mittal · Dipti Chourasia $\cdot$ Niraj Kumari • \\ Narendra Krishnani $\cdot$ Uday C. Ghoshal
}

Received: 4 August 2012/Accepted: 21 April 2013/Published online: 19 May 2013

(C) The International Gastric Cancer Association and The Japanese Gastric Cancer Association 2013

\begin{abstract}
Background Activity of cytochrome P450 (CYP), a polymorphic carcinogen-activating enzyme, is exaggerated following Helicobacter pylori infection. We studied the role of CYP2E1, CYP1A2 (rs762551), and CYP1A1 (rs4646903) polymorphisms in association with $H$. pylori infection in gastric carcinogenesis.

Methods Genotyping of CYP2E1 (96-bp insertion), CYP1A2 (164A to C), and CYP1A1 (3801C to T) was carried out in $88,76,53$, and 170 patients with gastric cancer (GC), functional dyspepsia (FD), peptic ulcer (PU), and healthy controls (HC), respectively. Serum IgG antibody (all subjects), rapid urease test, and histology (GC, FD, and PU patients) were used to test for $H$. pylori.

Results CYP2E1 gene polymorphism was more common among patients with GC than $\mathrm{HC}$ and PU [48/88 (54.5\%) vs. $67 / 170$ (39.4\%); OR 1.9, $95 \%$ CI 1.1-3.2, $p=0.016)$ and [PU 18/53 (34 \%); OR 2.3 (1-4.7), $p=0.02$ ]. CYP1A2 CC or CT genotypes was lower among patients with $\mathrm{GC}$ than $\mathrm{HC}$ [50/ $88(56.8 \%)$ vs. $120 / 170$ (70.6\%); OR 0.54 (0.31-0.92),
\end{abstract}

\footnotetext{
U. Ghoshal ( $\bowtie)$

Department of Microbiology, Sanjay Gandhi Post Graduate Institute of Medical Sciences, Lucknow 226014, India e-mail: ujjalaghoshal@yahoo.co.in

S. Tripathi · S. Kumar · D. Chourasia · U. C. Ghoshal Department of Gastroenterology, Sanjay Gandhi Postgraduate Institute of Medical Sciences, Lucknow 226014, India

B. Mittal

Department of Genetics, Sanjay Gandhi Postgraduate Institute of Medical Sciences, Lucknow 226014, India

N. Kumari · N. Krishnani

Department of Pathology, Sanjay Gandhi Postgraduate Institute of Medical Sciences, Lucknow 226014, India
}

$p=0.023]$. CYP1A1 polymorphism and CYP1A1-CYP1A2 haplotypes were comparable among different groups. CYP2E1 was also more common in patients with $\mathrm{GC}$ than $\mathrm{HC}$ and $\mathrm{PU}$ in the absence of $H$. pylori [33/60 (55 \%) vs. 19/52 (36.5\%); OR 4 (1.5-11.4), $p=0.007$ and PU 7/22 (31.8\%); OR 3.4 $(1-11.6), p=0.05]$. CYP1A1 (CT $+\mathrm{TT})$ was more common in patients with GC than PU in presence of $H$. pylori $[17 / 26$ $(65.4 \%)$ vs. 11/29 (38 \%); OR $3.0(1.03-9.3), p=0.045]$. Conclusions The presence of CYP2E1 (96-bp insertion) is associated with increased risk of GC even in absence of H. pylori. CYP1A2 CC or CT is associated with reduced risk of GC.

Keywords Genetic polymorphism - Helicobacter pylori . Gastric cancer · Peptic ulcer - Functional dyspepsia

\section{Introduction}

Although the incidence of gastric cancer (GC) has recently declined in several countries, it is still the second most common cause of cancer-related mortality worldwide [1,2]. Several risk factors have been identified in the multistep and multifactorial process of gastric carcinogenesis [3, 4]. Infection with Helicobacter pylori (H. pylori) is considered as one of the most important risk factors and to be responsible for $5.5 \%$ of the global health burden of all infection-associated cancers [5]. In 1994, the World Health Organization classified $H$. pylori as a group I carcinogen [6].

Of $50-80 \%$ of the world's population infected with $H$. pylori, only about $1 \%$ of infected individuals develop malignancy [7, 8]. In some Asian and African countries, in spite of a high prevalence of $H$. pylori infection, the incidence of GC is low [9]. Studies based on differences in pathogenicity of $H$. pylori alone failed to explain this 
enigma $[9,10]$. This result indicates that, in addition to $H$. pylori, host genetic factors may play a significant role in gastric carcinogenesis.

Various dietary and environmental carcinogens are known to play important roles in gastric carcinogenesis. Carcinogens and toxins entering the human body are metabolized and eliminated via a xenobiotic pathway [11]. Xenobiotic metabolism consists of phase I and phase II reactions. Cytochrome P450 (CYP) are the most important phase I enzymes [12]. Phase I enzymes catalyze activation of pro-carcinogens to active electrophilic intermediates, which act as substrates for phase II enzymes, by which carcinogens are detoxified and excreted from the body [13]. However, the electrophilic intermediates can interact with biological macromolecules (DNA, RNA, and proteins), leading to formation of adducts that initiate carcinogenesis. The genes encoding the CYP family of enzymes are polymorphic and therefore lead to interindividual variation in enzyme activity and in turn to cancer susceptibility [14, 15]. The enzymes encoded by CYP2E1, CYP1A1, and CYP1A2 genes of the CYP super gene family are involved in activation of various carcinogens such as polycyclic aromatic hydrocarbons, nitrosamines, and heterocyclic amines [16-18]. A 96-bp insertion polymorphism in the 5 -flanking region has been recently reported in the regulatory region of the CYP2E1 gene that leads to an increase in enzyme activity [19]. CYP1A1 gene exhibits a 3801C to T substitution (CYP1A1*2) in exon 7 (rs4646903), creating an MspI restriction site and resulting in threefold increase in enzyme activity $[20,21]$. CYP1A2 gene exhibits a 164A to C (rs762551) transition (CYP1A2*1F), which is associated with decreased enzyme activity [22]. Polymorphisms of these genes have been associated with various malignancies [23-25]. However, there are few data on the association of the CYP1A1 Msp1 polymorphism and no data on the association of CYP2E1 (96-bp insert) and CYP1A2*1F-164A to C polymorphism with GC.

In addition to the effect of various polymorphisms on CYP enzyme activity, $H$. pylori infection is also known to reduce enzyme activity [26]. There is no study on polymorphisms of CYP2E1, CYP1A1, and CYP1A2 genes in association with $H$. pylori infection. Therefore, we investigated the association of CYP2E1 (96-bp insertion), CYP1A1*2, and CYP1A2*1F polymorphisms in patients with GC as compared with diseased and healthy controls, with particular attention to the effect of these polymorphisms in relationship to $H$. pylori infection.

\section{Methods}

\section{Subjects}

Eighty-eight patients with histology-confirmed non-cardia GC, 76 with functional dyspepsia (FD), and 53 with peptic ulcer (PU) were included in the study. Patients with FD and PU served as diseased controls. Patients on anti-secretory drugs or those treated with anti-H. pylori therapy in the past were excluded. One hundred and seventy volunteers from the community (age- and sex matched) were also included as healthy controls (HC). Data on tobacco consumption was obtained by a standard questionnaire enquiring about smoking (in the form of bidi or cigarettes) and tobacco chewing (in the form of surti, gutka, and paan with surti). The study protocol was approved by the Institutional Ethics Committee, and written informed consent was obtained from all the subjects.

\section{Clinical diagnosis and sample collection}

Diagnosis of GC was made by histological examination of biopsies obtained endoscopically or at surgery. If gastric neoplasm was diagnosed, it was further subclassified into intestinal or diffuse type using a standard classification of adenocarcinoma or primary gastric lymphoma (PGL) [27]. Patients with FD were diagnosed using standard criteria [28]. Diagnosis of PU was made by finding benignappearing ulcers in the stomach or duodenum at upper gastrointestinal tract (UGI) endoscopy.

Five milliliters of blood was collected from each subject for $H$. pylori serology (IgG) and genotyping. The quantity and purity of DNA were checked by $1.0 \%$ agarose gel electrophoresis and also by the ratio of optical density (OD) at 260 and $280 \mathrm{~nm}$. Blood was stored at $-40{ }^{\circ} \mathrm{C}$ until use.

\section{Diagnosis of $H$. pylori infection}

Helicobacter pylori infection was diagnosed by rapid urease test (RUT), histology, and enzyme-linked immunosorbent assay (ELISA) for HpIgG antibodies. Two biopsies, one each from the antrum and body of the stomach, were used for RUT at the time of endoscopy [29]. Histology utilized hematoxylin and eosin (H\&E) and Giemsa stains. The serum level of anti-H. pylori IgG antibody was estimated using a commercially available kit (Biohit gastrosoft, Finland) according to manufacturer's instructions. Positive results in any two of these three tests were considered diagnostic of $H$. pylori infection.

\section{DNA extraction and genotyping}

Genomic DNA was extracted from venous blood containing EDTA using a commercially available kit (AuPrep; Life Technologies, India) as per manufacturer's instructions.

Genotyping of CYP1A1 and CYP1A2 genes was performed by polymerase chain reaction-restriction fragment length polymorphism (PCR-RFLP) and that of CYP2E1 by PCR [20, 22, 25, 30]. In case of CYP2E1 genotyping, absence 

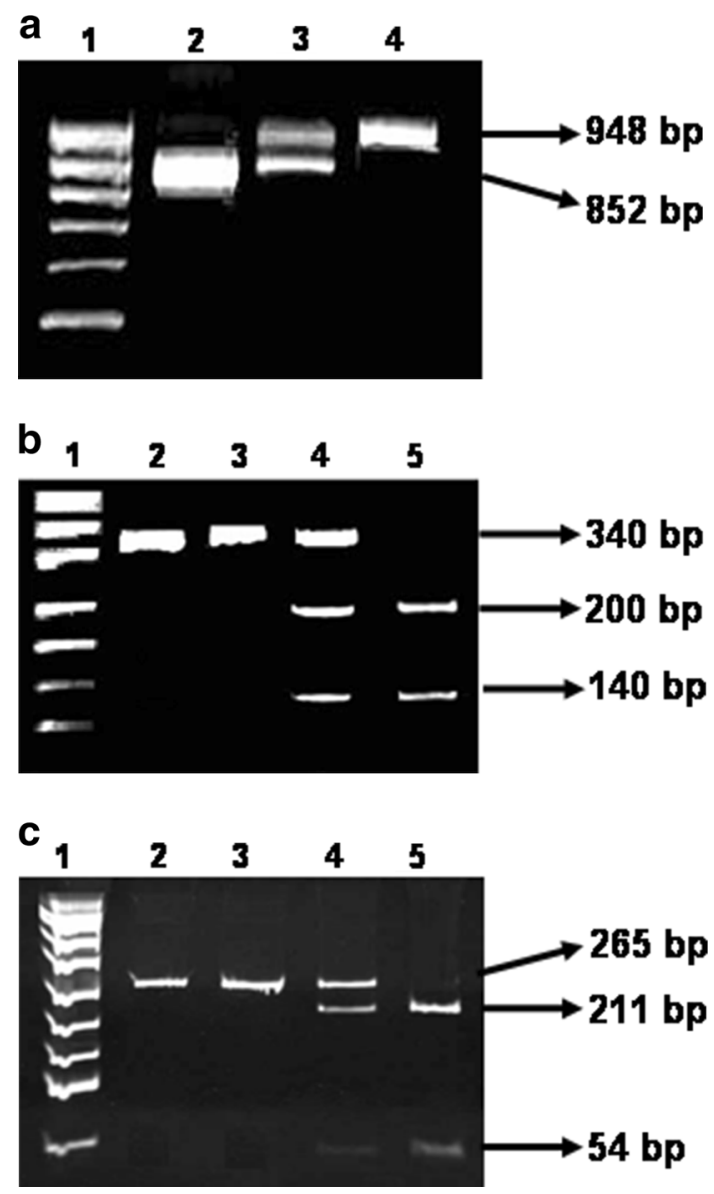

Fig. 1 Representative gel pictures. a CYP2E1 (96-bp insertion) PCR product: lane 1 molecular marker, lane 2 0/0 (no insert), lane 3 0/96 (heterozygous with 96-bp insert), lane 4 96/96 (homozygous with 96-bp insert). b CYP1A1 (3801C to T) PCR-RFLP: lane 1 molecular marker, lane 2 undigested $\mathrm{PCR}$ product, lane $3 \mathrm{CC}$, lane $4 \mathrm{CT}$, lane 5 TT. c CYP1A2 (164A to C) PCR-RFLP: lane 1 molecular marker, lane 2 undigested $\mathrm{PCR}$ product, lane $3 \mathrm{CC}$, lane $4 \mathrm{CA}$, lane $5 \mathrm{AA}$

of the insert was represented as $0 / 0$. Presence of $96-b p$ insert in the CYP2E1 gene was represented as 0/96 (in heterozygous form) and 96/96 (in homozygous form) (Fig. 1a). The PCR products were digested overnight by restriction endonucleases $M s p 1$ for CYP1A1 and Bsp 120I for CYP1A2 polymorphisms at $37{ }^{\circ} \mathrm{C}$ and were thereafter separated by $2 \%$ agarose gel electrophoresis. For the CYP1A1 gene, the genotypes identified were homozygous wild (CC), heterozygous (CT), and homozygous variant (TT) (Fig. 1b). For the CYP1A2 gene, the genotypes identified were wild (AA), heterozygous (AC), and variant (CC) (Fig. 1c). Genotyping results were confirmed by independent sequencing of $5 \%$ samples; results were reproducible with no discrepancy.

\section{Statistical analysis}

All comparison of categorical data and Hardy-Weinberg equilibrium were evaluated by chi squared $\left(\chi^{2}\right)$ test. $p$ values less than 0.05 were considered significant. Binary logistic regression was used to estimate risks as odds ratio (OR) with $95 \%$ confidence intervals (CI). In addition, haplotype analysis was used to estimate the frequency of unknown phase (joint distribution of genetic markers at a single disease locus or chromosome), among the patients with $\mathrm{GC}, \mathrm{FD}, \mathrm{PU}$, and $\mathrm{HC}$, in relationship to $H$. pylori infection by software SNP analyzer 2.0 and SPSS ver. 15 (SPSS, Chicago, IL, USA).

\section{Results}

Demographic data of the subjects

All the patients and controls recruited in this study were comparable with respect to age and gender. Tobacco habit was similar in all the groups (Table 1).

Clinical details of patients with GC

Of 88 patients with GC included in the study, 28 (31.8\%) presented with dyspepsia with or without weight loss, 18 $(20.5 \%)$ with gastric outlet obstruction, $22(25 \%)$ with upper gastrointestinal bleeding (UGI bleed), 13 (14.7\%) with dysphagia, and 3 (3.4\%) with malignant ascites. One patient $(1.1 \%)$ presented with both dysphagia and UGI bleed. Two patients $(2.3 \%)$ presented with both gastric outlet obstruction and UGI bleed. One patient $(1.1 \%)$ presented with acanthosis nigricans and dyspepsia.

Histopathology of tumor

Of 108 patients undergoing endoscopy for suspected gastric neoplasm with histological diagnosis, 88 were included. All the patients included had non-cardia GC. Fifty (57\%) patients had intestinal GC, 28 (32\%) diffuse GC, and $8(9 \%)$ had PGL. In two patients (2\%), the tumor was unclassified.

\section{Clinical details of patients with PU}

Of 53 patients with PU, 38 (71.7\%) had duodenal ulcer (DU), $12(22.6 \%)$ had gastric ulcer (GU), and $3(5.7 \%)$ had both. Of 53 patients with PU, $22(41.5 \%)$ had associated diseases such as cirrhosis of liver $(n=5)$ and ulcerative colitis $(n=1)$ or presented with upper gastrointestinal bleeding $(n=16)$.

Results of $H$. pylori infection

H. pylori infection was more common in patients with FD than GC [41/73(57\%) vs. 26/86(30\%), $p=0.05]$ by criteria (two 
Table 1 Demographic data, tobacco habits, and Helicobacter pylori positivity in different groups

\begin{tabular}{|c|c|c|c|c|c|}
\hline & GC & FD & PU & $\mathrm{HC}$ & $p$ value \\
\hline Age in years $(\text { mean } \pm \mathrm{SD})^{\mathrm{a}}$ & $54.3 \pm 11.8$ & $52.4 \pm 11.6$ & $51.8 \pm 14.5$ & $52.7 \pm 11.4$ & NS \\
\hline Gender $(\text { male })^{b}$ & $64(72.7 \%)$ & $52(68.4 \%)$ & $39(73.6 \%)$ & $127(74.7 \%)$ & NS \\
\hline \multicolumn{6}{|l|}{ Tobacco habits $^{\mathrm{c}}$} \\
\hline Chewing of Surti or Gutka & $30 / 83(36.2 \%)$ & $23 / 71(32.4 \%)$ & $16 / 48(33.4 \%)$ & $46 / 152(30 \%)$ & NS \\
\hline Smoking status & $28 / 83(33.7 \%)$ & $21 / 70(30 \%)$ & $13 / 48(27.4 \%)$ & $27 / 152(18 \%)$ & NS \\
\hline Both & $19(23.4 \%)$ & $11 / 70(15.7 \%)$ & $6(13.3 \%)$ & $14(9 \%)$ & NS \\
\hline No tobacco use & $42 / 83(50.6 \%)$ & $37 / 71(52.1 \%)$ & $26 / 48(54.2 \%)$ & $93 / 152(61 \%)$ & NS \\
\hline \multicolumn{6}{|l|}{ Helicobacter pylori infection ${ }^{\mathrm{c}}$} \\
\hline RUT & $21 / 86(24 \%)$ & $26 / 73(73 \%)$ & $21 / 50(42 \%)$ & - & NS \\
\hline Histopathology & $30 / 87(35 \%)$ & $48 / 74(65 \%)$ & $25 / 42(60 \%)$ & - & $\mathrm{GC}$ vs. $\mathrm{FD}=0.03$ \\
\hline Anti-H. pylori IgG ELISA & $56 / 88(64 \%)$ & $43 / 74(57 \%)$ & $31 / 52(60 \%)$ & $111(68 \%)$ & NS \\
\hline H. pylori status ( 2 positive of 3 ) & $26 / 86(30 \%)$ & $41 / 73(56 \%)$ & $29 / 51(57 \%)$ & - & $\mathrm{GC}$ vs. $\mathrm{FD}=0.05$ \\
\hline
\end{tabular}

$G C$ gastric cancer, $F D$ functional dyspepsia, $P U$ peptic ulcer, $H C$ healthy control, $N S$ not significant

${ }^{a}$ Age: $\mathrm{GC}$ vs. FD, $p=0.4$; GC vs. $\mathrm{PU}, p=0.22$, GC vs. $\mathrm{HC}, p=0.32$

${ }^{\mathrm{b}}$ Gender: $\mathrm{GC}$ vs. FD, $p=0.6$; $\mathrm{GC}$ vs. $\mathrm{PU}, p=0.8$; $\mathrm{GC}$ vs. $\mathrm{HC}, p=0.7$

c Data were missing in some cases

positive of three tests). H. pylori was detected less frequently among patients with GC than HC [26/86 (30 \%) vs. 111/163 $(68 \%) ; p=0.001]$. Results of IgG ELISA were comparable among the different groups (Table 1).

Results of CYP2E1, CYP1A1, and CYP1A2 polymorphism

Genotype frequencies of CYP2E1, CYP1A1 and CYP1A2 genes are summarized in Table 2. Frequencies of genotypes and alleles were in Hardy-Weinberg equilibrium in controls $\left(\chi^{2}\right.$ test: $p$ value for patients with $\mathrm{PU}=0.92,0.11$, 0.54 ; patients with $\mathrm{FD}=0.07,0.39,0.33$; $\mathrm{HC}=0.82$, $0.16,0.19)$ for genotyping of CYP2E1, CYP1A1, and CYP1A2, respectively. The analysis comparing the risk of GC associated with CYP2E1, CYP1A1, and CYP1A2 genotypes and alleles is shown in Table 2.

\section{Association of CYP2E1 gene polymorphisms and risk of $G C$}

Frequency of the heterozygous $96 / 0$ genotype was higher in patients with GC and conferred twofold risk in reference to

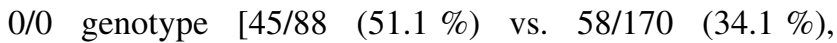
$p=0.009$; OR $2.01,95 \%$ CI $1.2-3.5]$ in comparison to HC. Presence of the 96-bp insert either in homozygous or heterozygous form was also associated with twofold-higher risk of GC [48/88(54.5\%) vs. 67/170 (39.4\%), $p=0.016$; OR $1.9,95 \%$ CI 1.1-3.2].

Patients with GC had a higher frequency of $96 / 0$ genotype in comparison to patients with PU, which conferred more than twofold risk in reference to $0 / 0$ genotype [45/
88(51.1\%) vs. $15 / 53(30.2 \%), p=0.017$; OR $2.4,95 \%$ CI 1.2-5]. Presence of he 96-bp insert in either the homozygous or heterozygous form was associated with more than twofold risk [GC $(54.5 \%)$ vs. PU (34\%), $p=0.02$; OR 2.3, $95 \%$ CI 1-4.7].

However, CYP2E1 genotype and allele frequency were comparable between patients with GC and FD (Table 3).

\section{Association between CYP1A1 genotypes and risk of GC}

The CC, CT, and TT genotype frequencies were comparable among various groups and did not confer any significant risk of GC (Table 3).

\section{Association between CYP1A2 genotypes and risk of GC}

Presence of homozygous variant (CC) in reference to homozygous wild (AA) genotype was associated with reduced risk of $\mathrm{GC}[p=0.012$; OR $0.48 \quad 95 \%$ CI 0.27-0.85]. Similarly, presence of CC or CA genotypes (C carriers) was associated with reduced risk of GC in reference to AA genotype $[50 / 88(56.8 \%)$ vs. $120 / 170$ (70.6\%); $p=0.023$; OR 0.54, $95 \%$ CI 0.31-0.92], although CYP1A2 genotype and allele frequency were similar among patients with GC in comparison to patients with FD and PU and did not confer any risk (Table 3).

Haplotype frequency of CYP1A1-CYP1A2 genotypes and risk of GC

Haplotypes were evaluated for CYP1A1 and CYP1A2 genes located in the same chromosome with emphasis on 


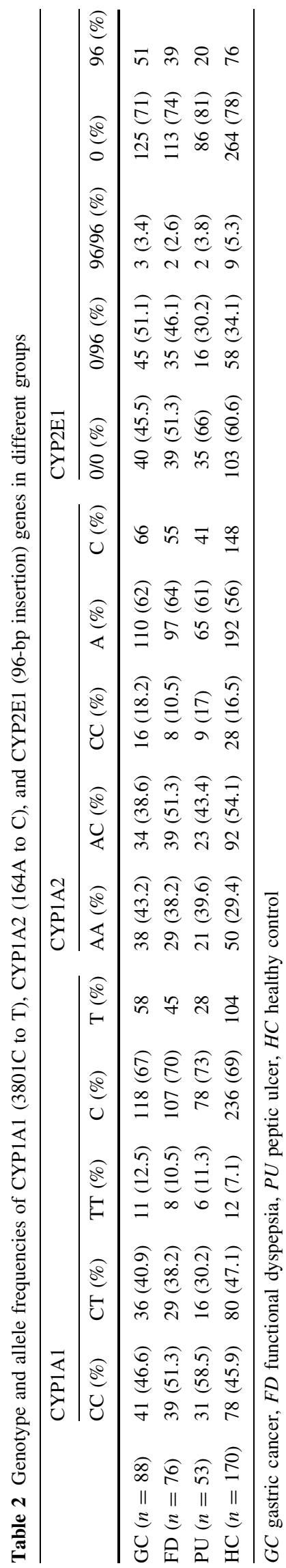

combinations of variant haplotypes, which may be more likely to influence change in CYP enzyme activity. Four haplotypes-normal (3801C-164A), slow (3801C-164C), fast (3801T-164C), and very fast (3801T-164A) - were constructed. Frequency of haplotype T-C and and T-A was higher in GC compared to controls (Table 4).

Association between CYP2E1, CYP1A1, and CYP1A2 genotypes and risk of $\mathrm{GC}$ in relationship to $H$. pylori infection

Frequency of CYP2E1, CYP1A1, and CYP1A2 genotypes in $H$. pylori-infected and noninfected individuals is presented in Table 5. For analysis, both homozygous and heterozygous carriers of the variant allele were included in one group. Presence of the 96-bp insert in CYPE1 was associated with higher risk of $\mathrm{GC}$ in absence of $H$. pylori [GC $(55 \%)$ vs. PU (32\%): $p=0.068$; OR $1.8 ; 95 \%$ CI $0.9-7.3$ and $\mathrm{GC}(55 \%)$ vs. $\mathrm{HC}(37 \%): p=0.052$; OR 2.12 (1.0-4.5). In presence of $H$. pylori infection, the 96-bp insert did not confer significant risk. CYP1A1 C carriers conferred a higher risk of GC in the presence of $H$. pylori infection [GC (65\%) vs. FD (41\%): $p=0.059$; OR 2.7; $95 \% \mathrm{CI} 0.96-7.39$, and GC $(65 \%)$ vs. PU (38\%): $p=0.045 ;$ OR $3.0 ; 95 \%$ CI 1.03-9.3], although the CYP1A2 genotype was associated with reduced risk of GC in presence of $H$. pylori [GC $(50 \%)$ vs. HC $(75 \%)$ : $p=0.016$; OR $0.34 ; 95 \%$ CI $0.14-0.81]$.

\section{Association of CYP2E1, CYP1A1, and CYP1A2} genotypes and histological subtypes of tumor

Frequency of the CYP2E1, CYP1A1, and CYP1A2 genotypes in relationship to type of tumor is shown in Table 6. Presence of the CYP2E1 96-bp insert (0/96 or 96/96) conferred a threefold-higher risk of diffuse than intestinal type of tumor $[20 / 28$ (71.4\%) vs. 23/50 (46\%); $p=0.035$; OR 2.99; $95 \%$ CI 1-8.3]. Similarly, the presence of CYP1A1 CT or TT genotypes was associated with higher risk of diffuse than intestinal type of tumor [20/28 (71.4\%) vs. $24 / 50$ (48 \%); $p=0.04$; OR 2.87; $95 \% \mathrm{CI}$ 1-7.9]. CYP1A2 genotype frequency was similar between the two subtypes of tumor.

\section{Discussion}

In the present study, the frequency of CYP2E1, CYP1A1, and CYP1A2 genotypes suggests a possible role in gastric carcinogenesis as follows: (1) presence of CYP2E1 (96-bp insert) was associated with twofold-higher risk of GC rather than $\mathrm{HC}$ and $\mathrm{PU}$ and was conferred in absence of H. pylori; (2) presence of CYP1A2 CC or CA genotypes 
Table 3 Analysis of CYP1A1 (3801C to T), CYP1A2 (164A to C), and CYP2E1 (96-bp insertion) genotype and allele frequency data

\begin{tabular}{|c|c|c|c|}
\hline Gene & $\begin{array}{l}\text { GC vs. FD OR } \\
(95 \% \mathrm{CI})\end{array}$ & $\begin{array}{l}\text { GC vs. PU OR } \\
(95 \% \text { CI })\end{array}$ & $\begin{array}{l}\text { GC vs. } \mathrm{HC} \mathrm{OR}^{\mathrm{A}} \\
(95 \% \mathrm{CI})\end{array}$ \\
\hline \multicolumn{4}{|l|}{ CYP1A1 } \\
\hline TT vs. $\mathrm{CC}^{\mathrm{B}}$ & $1.27(0.46-3.5)$ & $1.37(0.45-4)$ & $1.8(0.7-4.4)$ \\
\hline $\mathrm{CT}$ vs. $\mathrm{CC}$ & $1.19(0.6-2.3)$ & $1.65(0.77-3.5)$ & $0.87(0.5-1.5)$ \\
\hline Carriers of $\mathrm{T}$ vs. $\mathrm{CC}$ & $1.2(0.65-2.2)$ & $1.57(0.79-3.1)$ & $0.98(0.6-1.65)$ \\
\hline $\mathrm{T}$ vs. $\mathrm{C}$ allele $\mathrm{C}^{\mathrm{C}}$ & $1.2(0.7-1.9)$ & $1.4(0.8-2.3)$ & $1.1(0.8-1.63)$ \\
\hline \multicolumn{4}{|l|}{ CYP1A2 } \\
\hline $\mathrm{CC}$ vs. $\mathrm{AA}^{\mathrm{B}}$ & $0.69(0.35-1.34)$ & $0.8(0.4-1.75)$ & $0.48(0.27-0.85)^{\mathrm{a}}$ \\
\hline CA vs. AA & $1.5(0.56-4)$ & $0.98(0.37-2.6)$ & $0.74(0.35-1.6)$ \\
\hline Carriers of $\mathrm{C}$ vs. AA & $0.83(0.44-1.6)$ & $0.87(0.4-1.7)$ & $0.54(0.31-0.92)^{\mathrm{b}}$ \\
\hline C vs. A allele ${ }^{C}$ & $1.0(0.7-1.7)$ & $0.9(0.6-1.6)$ & $0.78(0.5-1.1)$ \\
\hline \multicolumn{4}{|l|}{ CYP2E1 } \\
\hline $96 / 96$ vs. $0 / 0^{\mathrm{B}}$ & $1.44(0.23-9.14)$ & $1.4(0.2-8.9)$ & $0.9(0.23-3.5)$ \\
\hline $96 / 0$ vs. $0 / 0$ & $1.25(0.67-2.35)$ & $2.4(1.1-7.5)^{\mathrm{c}}$ & $2.0(1.2-3.5)^{\mathrm{d}}$ \\
\hline Carriers of $96-b p$ insert vs. $0 / 0$ & $1.3(0.68-2.3)$ & $2.3(1-4.7)^{\mathrm{e}}$ & $1.9(1.1-3.2)^{f}$ \\
\hline 96 vs. 0 allele ${ }^{\mathrm{C}}$ & $1.2(0.7-1.9)$ & $1.75(0.97-3.1)^{\mathrm{g}}$ & $1.42(0.9-2.1)$ \\
\hline
\end{tabular}

$G C$ gastric cancer, $F D$ functional dyspepsia, $P U$ peptic ulcer, $H C$ healthy control, $C I$ confidence interval, $O R$ odds ratio

A Age- and gender-adjusted odds ratio except for allele frequency comparison

B $\mathrm{CC}, \mathrm{AA}$, and $0 / 0$ taken as a reference in genotypes

${ }^{\mathrm{C}} \mathrm{C}, \mathrm{A}$, and 0 allele taken as a reference in alleles status for CYP1A1, CYP2A2 and CYP2E1, respectively; for risk analysis assuming no association with disease outcome $(\mathrm{OR}=1)$

${ }^{\mathrm{a}} \quad p$ value $=0.012 ;{ }^{\mathrm{b}} p$ value $=0.023,{ }^{\mathrm{c}} p$ value $=0.017,{ }^{\mathrm{d}} p$ value $=0.009,{ }^{\mathrm{e}} p$ value $=0.02,{ }^{\mathrm{f}} p$ value $=0.016,{ }^{\mathrm{g}} p$ value $=0.06$

(C carriers) was associated with reduced risk of GC and it also was conferred in presence of $H$. pylori as compared to HC; (3) CYP1A1 CT or TT genotypes (T carriers) showed higher risk of $\mathrm{GC}$ in presence of $H$. pylori as compared to disease controls (FD and PU); (4) CYP1A1 T carriers and CYP2E1 96-bp insert (0/96 or 96/96) also increased the GC risk, especially for diffuse type rather than intestinal type of tumor.

Host genetic factors in the pathogenesis of GC have been evaluated in a few studies, particularly in relationship to $H$. pylori infection $[31,32]$. Therefore, in this study we aimed to evaluate the role of CYP2E1 (96-bp insertion polymorphism), CYP1A1 (MspI RFLP), and CYP1A2 $(-164 \mathrm{~A}$ to $\mathrm{C})$ genes in gastric carcinogenesis in association with $H$. pylori infection. This is the first study in which the roles of CYP2E1 (96-bp insert) and CYP1A2*1F ($164 \mathrm{~A}$ to $\mathrm{C}$ ) polymorphisms have been evaluated in $\mathrm{GC}$ in relationship to $H$. pylori infection.

CYP450 enzymes catalyze activation of inactive procarcinogens to active carcinogens. Intraindividual responses of a host against activation of pro-carcinogens depend on enzyme-related gene polymorphisms. Therefore, any polymorphism that will lead to increase in activity of the enzyme should be associated with enhanced risk of cancer. In contrast, a polymorphism causing decrease in activity of the enzyme should act as a protective factor for cancer. Hence, the complexity of risk assessment depends on the polymorphic gene variant products involved in pro- and anti-carcinogenic interactions [33].

The results of the present study show a higher frequency of CYP2E1 (96-bp insert) in patients with GC to be a risk factor of gastric carcinogenesis, similar to that of esophageal [34] and rectal cancer [25]. Presence of the 96-bp insert in the CYP2E1 gene is known to be associated with increased enzyme activity [19]. The CYP2E1 enzyme is mainly involved in metabolic activation of $N$-nitrosamines (a well-defined factor for gastric carcinogenesis) [35]. Therefore, the CYP2E1 genotype frequency observed in the present study is in accordance with this hypothesis. Similarly, the CYP1A1 gene 3801C to $\mathrm{T}$ transition is known to be associated with increased activity [20]. However, in the present study the presence of the CYP1A1 $\mathrm{T}$ allele was not associated with risk of GC. A recent metaanalysis reported by Guo and Guo [36] was in agreement with our observations for this polymorphism. Another study at our institute had also shown no association between CYP1A1 gene polymorphism and esophageal cancer [37]. The large EPIC-EURGAST case-control study also supported these findings for polymorphism of CYP1A1 [38]. In the case of the CYP1A2 gene, $-164 \mathrm{~A}$ to $\mathrm{C}$ substitution leads to a decrease in enzyme activity [22]. Thus, carriers of the $\mathrm{C}$ allele are expected to be at reduced risk of cancer. In the present study, the presence of the CC genotype conferred a reduced risk of GC compared to the 
Table 4 Association of CYP2A1-CYP1A2 haplotypes in the risk of gastric cancer

\begin{tabular}{|c|c|c|c|c|c|c|c|}
\hline Haplotypes & $\begin{array}{l}\mathrm{GC} \\
(n=174)^{\mathrm{a}}\end{array}$ & $\begin{array}{l}\mathrm{PU} \\
(n=104)^{\mathrm{a}}\end{array}$ & $\begin{array}{l}\text { FD } \\
(n=150)^{\mathrm{a}}\end{array}$ & $\begin{array}{l}\mathrm{HC} \\
(n=338)^{\mathrm{a}}\end{array}$ & $\begin{array}{l}\text { GC vs. HC OR }{ }^{b} \\
(95 \% \mathrm{CI})\end{array}$ & $\begin{array}{l}\text { GC vs. PU OR } \\
(95 \% \mathrm{CI})\end{array}$ & $\begin{array}{l}\text { GC vs. FD OR } \\
(95 \% \text { CI })\end{array}$ \\
\hline $\mathrm{A}$ & $61(35.0 \%)$ & $39(37.5 \%)$ & $56(37.3 \%)$ & $133(39.3 \%)$ & Reference & Reference & Reference \\
\hline $\mathrm{CC}$ & $56(32.2 \%)$ & $38(36.5 \%)$ & $50(33.3 \%)$ & $102(30.2 \%)$ & $1.19(0.77-1.87)$ & $0.94(0.53-1.67)$ & $1.03(0.61-1.74)$ \\
\hline TA & $48(27.6 \%)$ & $26(25.0 \%)$ & $40(26.7 \%)$ & $89(26.3 \%)$ & $-1.87)$ & $1.18(0$ & $1.10(0.6$ \\
\hline $\mathrm{TC}$ & $9(5.2 \%)$ & $1(1.0 \%)$ & $4(2.7 \%)$ & $14(4.1 \%)$ & $1.40(0.58-3.42)$ & $5.75(0.70-7.21)$ & $2.07(0.60-7.08)$ \\
\hline
\end{tabular}

$G C$ gastric cancer, $F D$ functional dyspepsia, $P U$ peptic ulcer, $H C$ healthy control, $C I$ confidence interval

${ }^{a}$ Number represents total number of chromosomes; frequency of combination equivalent to zero in any cell for CYP2A1 or CYP2A2 was not included in haplotype analysis

b OR, age- and gender-adjusted odds ratio

${ }^{\mathrm{c}} \mathrm{CA}$ taken as a reference for risk analysis

Table 5 Genotype frequencies of CYP1A1, CYP1A2, and CYP2E1 in relationship to Helicobacter pylori infection

\begin{tabular}{|c|c|c|c|c|c|c|}
\hline \multirow[b]{2}{*}{ H. pylori $\rightarrow$} & \multicolumn{2}{|c|}{ CYP1A1 (CT + TT vs. CC) } & \multicolumn{2}{|c|}{ CYP1A2 (CC + AC vs. AA) } & \multicolumn{2}{|c|}{ CYP2E1 (0/96 + 96/96 vs. 0/0) } \\
\hline & Positive & Negative & Positive & Negative & Positive & Negative \\
\hline $\mathrm{GC}(n=86)$ & $17 / 9^{\mathrm{A}}$ & $29 / 31$ & $13 / 13$ & $36 / 34$ & $13 / 13$ & $33 / 27$ \\
\hline $\mathrm{FD}(n=73)$ & $17 / 24$ & $17 / 15$ & $28 / 13$ & $19 / 13$ & $17 / 24$ & $19 / 13$ \\
\hline $\mathrm{PU}(n=51)$ & $11 / 18$ & $10 / 12$ & $16 / 13$ & $15 / 7$ & $9 / 20$ & $7 / 15$ \\
\hline $\mathrm{HC}(n=163)$ & $59 / 52$ & $29 / 23$ & $83 / 28$ & $33 / 19$ & $45 / 66$ & $19 / 33$ \\
\hline \multicolumn{7}{|l|}{$\mathrm{OR}^{\mathrm{B}}(95 \% \mathrm{CI})$} \\
\hline GC vs. FD & $2.7(0.96-7.39)^{\mathrm{a}}$ & $0.46(0.35-1.9)$ & $0.5(0.17-1.28)$ & $1.03(0.16-1.3)$ & $1.41(0.53-3.8)$ & $0.84(0.35-2.0)$ \\
\hline GC vs. PU & $3.03(1.03-9.3)^{b}$ & $1.12(0.4-3)$ & $1.3(0.5-3.2)$ & $0.8(0.28-2.35)$ & $2.2(0.7-6.7)$ & $1.8(0.9-7.3)^{\mathrm{c}}$ \\
\hline GC vs. HC & $1.1(0.5-2.2)$ & $0.74(0.4-1.56)$ & $0.34(0.14-0.8)^{\mathrm{d}}$ & $0.86(0.4-1.8)$ & $1.47(0.7-3.46)$ & $2.12(1.0-4.5)^{\mathrm{e}}$ \\
\hline
\end{tabular}

$G C$ gastric cancer, $F D$ functional dyspepsia, $P U$ peptic ulcer, $H C$ healthy control

A Total no. variant carrier genotypes/total no. wild genotype present in each $H$. pylori-infected and noninfected group

B $\mathrm{OR}$, age- and gender-adjusted odds ratio

${ }^{\mathrm{a}} p$ value $=0.059 ;{ }^{\mathrm{b}} p$ value $=0.045,{ }^{\mathrm{c}} p$ value $=0.068,{ }^{\mathrm{d}} p$ value $=0.016,{ }^{\mathrm{e}} p$ value $=0.052$

Table 6 Frequency of CYP1A1, CYP1A2, and CYP2E1 genotypes in relationship to diffuse and intestinal subtypes of tumor

\begin{tabular}{|c|c|c|c|c|c|c|}
\hline \multirow{2}{*}{$\begin{array}{l}\text { Gene } \\
\text { Tumor type }(n=88)^{\mathrm{A}}\end{array}$} & \multicolumn{2}{|l|}{ CYP1A1 } & \multicolumn{2}{|l|}{ CYP1A2 } & \multicolumn{2}{|l|}{ CYP2E1 } \\
\hline & $\mathrm{CC}$ & $\mathrm{T}$ carriers $(\%)$ & AA & $\mathrm{C}$ carriers $(\%)$ & $0 / 0$ & 96-bp insert carriers $(\%)$ \\
\hline Diffuse $(n=28)$ & 8 & $20(71.4)$ & 12 & $16(57.1)$ & 8 & $20(71.4)$ \\
\hline Intestinal $(n=50)$ & 26 & $24(48)$ & 18 & $32(64)$ & 27 & $23(46)$ \\
\hline $\mathrm{P} ; \mathrm{OR}^{\mathrm{B}}(95 \% \mathrm{CI})$ & Reference & $\mathbf{2 . 8 7 ^ { \mathrm { a } } ( 1 . 0 - 7 . 9 )}$ & Reference & $0.7(0.27-1.9)$ & Reference & $2.99^{\mathrm{b}}(1-8.3 .0)$ \\
\hline
\end{tabular}

T carriers, individuals with CYP1A1 CT or TT genotypes; C carriers, individuals with CYP1A2 CA or CC genotypes; 96-bp insert carriers, individuals with CYP2E1 0/96 or 96/96 genotypes

A Tumor was unclassified in two patients

B Age- and gender-adjusted odds ratio

${ }^{\mathrm{a}} \quad p$ value $=0.04 ;{ }^{\mathrm{b}} p$ value $=0.035$

AA genotype. Similarly, carriers of the C allele genotype were also associated with reduced cancer risk. This is the first report on the association of CYP1A2*1F gene polymorphism and risk of GC.

H. pylori is considered to be an important risk factor for GC. Thus, the presence of $H$. pylori infection along with cancer susceptibility genotypes should further increase cancer risk, although CYP2E1 96/0 or 96/96 genotypes were associated with significant risk of GC in the absence but not in the presence of $H$. pylori. In contrast, CYP1A2 carriers of the $\mathrm{C}$ allele were associated with a lower risk of $\mathrm{GC}$ in the presence of $H$. pylori infection but not in its 
absence. These unexpected observations could be explained by the fact that $H$. pylori infection is known to be associated with a decrease in CYP enzyme activity [26]. CYP is a carcinogen-activating enzyme; therefore, decrease in its activity caused by $H$. pylori infection would reduce its carcinogen-activating potential and risk of cancer. Thus, the presence of the CYP2E1 (96-bp insert) and CYP1A2 genes and $H$. pylori infection have opposite effects on CYP enzyme activity. Furthermore, a study from our center examining the role of phase II xenobiotic metabolizing glutathione-S-transferase (GST) enzyme in gastric carcinogenesis also supports the observations of the present study $[39,40]$. Similar to the CYP enzyme, deletion of the GSTT1 gene of the GST supergene family leads to reduced enzyme activity [40]. Moreover, the presence of $H$. pylori infection is also known to be associated with reduced GST enzyme activity and increased cancer susceptibility [41]. Thus, deletion of the GSTT1 gene and presence of $H$. pylori both have the same effect on enzyme activity and cancer susceptibility [39]. In agreement, a recently completed study on polymorphisms of microsomal epoxide hydrolase $(\mathrm{mEH})$ phase II metabolizing enzyme also produced similar observations in this ethnic background. mEH 113Tyr-139Arg (fast allele) was associated with a significantly higher and lower risk of GC in the presence and absence of $H$. pylori infection [OR 2.61 (1.14-5.9), $\quad p=0.023$, and OR 0.36 (0.17-0.75), $p=0.006$, respectively]. Our data also showed that the CYP1A1 T carrier genotype was also associated with a higher risk of GC in the presence of $H$. pylori infection as compared to FD and PU. Patients with FD and PU had a higher frequency of $H$. pylori infection as compared to patients with GC, suggesting a possible mechanism of $H$. pylori-associated gastrointestinal disease development in the Indian enigma. This interesting observation is further supported by the prevailing Asian and African enigma where despite high $H$. pylori seroprevalence the annual incidence of GC is low and vice versa. Small sample size was, however, a limitation of the present study. Stratification within groups on the basis of $H$. pylori positivity may lead to type II statistical error. The small number of cases also resulted in inability to explore the combined effects of gene-environment interactions. Therefore, these observations need to be confirmed by future studies on a larger number of patients.

Diffuse and intestinal types of GC follow two distinct genetic pathways of carcinogenesis [42]. However, there are limited data on association of host genes with diffuse and intestinal types of tumor. In the present study, CYP1A1 CT or TT genotypes and CYP2E1 96-bp insert (0/ 96 or $96 / 96$ ) was associated with about three times higher risk of diffuse rather than intestinal type of tumor. In a previous study from our center, the GSTM1 null genotype conferred an eightfold risk of diffuse compared to intestinal type of tumor [43]. Polymorphisms in these genes could be used to identify individuals who are more likely to develop diffuse-type GC.

In conclusion, the present study shows that presence of the 96-bp insert in the regulatory region of CYP2E1 gene is a risk factor for GC. The risk conferred by the 96-bp insert of CYP2E1 gene was higher in the absence compared to the presence of $H$. pylori infection. The presence of $H$. pylori combined with the CYP1A1 T carrier genotype increases the risk of GC. However, the presence of $\mathrm{C}$ allele carriers of the CYP1A2 gene independently and in the presence of $H$. pylori is associated with a reduced risk of GC.

Acknowledgments The manuscript has not been previously published and is not under consideration by any other journal (except in the form of an abstract or as part of a published lecture or academic thesis). Financial support for this study was provided by Sanjay Gandhi Post Graduate Institute of Medical Sciences, Lucknow, India (PGI/DIR/RC/588/2005).

\section{References}

1. Parkin DM. Global cancer statistics in the year 2000. Lancet Oncol. 2001;2:533-43.

2. Parkin DM. International variation. Oncogene. 2004;23:6329-40.

3. Correa P. Human gastric carcinogenesis: a multistep and multifactorial process. First American Cancer Society award lecture on cancer epidemiology and prevention. Cancer Res. 1992;52: $6735-40$

4. Nomura A. Stomach cancer. In: Schottenfeld D, Fraumeni JF, editors. Cancer epidemiology and prevention, 2nd edn. New York: Oxford University Press; 1996. p. 707-724.

5. Parkin DM. The global health burden of infection-associated cancers in the year 2002. Int J Cancer. 2006;118:3030-44.

6. Schistosomes, Liver flukes and Helicobacter pylori: IARC working group on the evaluation of carcinogenic risks to humans. IARC Monogr Eval Carcinog Risks Hum. 1994;61:1-241.

7. Graham DY, Adam E, Reddy GT, et al. Seroepidemiology of Helicobacter pylori infection in India. Comparison of developing and developed countries. Dig Dis Sci. 1991;36:1084-8.

8. Parsonnet J, Friedman GD, Orentreich N, Vogelman H. Risk for gastric cancer in people with CagA-positive or CagA-negative Helicobacter pylori infection. Gut. 1997;40:297-301.

9. Singh K, Ghoshal UC. Causal role of Helicobacter pylori infection in gastric cancer: an Asian enigma. World J Gastroenterol. 2006; 12:1346-51.

10. Ghoshal UC, Tripathi S, Ghoshal U. The Indian enigma of frequent $H$. pylori infection but infrequent gastric cancer: is the magic key in Indian diet, host's genetic makeup, or friendly bug? Am J Gastroenterol. 2007;102:2113-4.

11. Gonzalez FJ. The role of carcinogen-metabolizing enzyme polymorphisms in cancer susceptibility. Reprod Toxicol. 1997; 11:397-412.

12. Guengerich FP. Update information on human P450s. Drug Metab Rev. 2002;34:7-15.

13. Guengerich FP, Shimada T. Activation of procarcinogens by human cytochrome P450 enzymes. Mutat Res. 1998;400:201-13.

14. Guengerich FP. Forging the links between metabolism and carcinogenesis. Mutat Res. 2001;488:195-209. 
15. Guengerich FP. Roles of cytochrome P-450 enzymes in chemical carcinogenesis and cancer chemotherapy. Cancer Res. 1988;48: 2946-54.

16. Guengerich FP, Kim DH, Iwasaki M. Role of human cytochrome P-450 IIE1 in the oxidation of many low molecular weight cancer suspects. Chem Res Toxicol. 1991;4:168-79.

17. McManus ME, Burgess WM, Veronese ME, et al. Metabolism of 2 -acetylaminofluorene and benzo( $a$ )pyrene and activation of food-derived heterocyclic amine mutagens by human cytochromes P-450. Cancer Res. 1990;50:3367-76.

18. Boobis AR, Lynch AM, Murray S, et al. CYP1A2-catalyzed conversion of dietary heterocyclic amines to their proximate carcinogens is their major route of metabolism in humans. Cancer Res. 1994;54:89-94.

19. McCarver DG, Byun R, Hines RN, Hichme M, Wegenek W. A genetic polymorphism in the regulatory sequences of human CYP2E1: association with increased chlorzoxazone hydroxylation in the presence of obesity and ethanol intake. Toxicol Appl Pharmacol. 1998;152:276-81.

20. Kawajiri K, Nakachi K, Imai K, et al. Identification of genetically high risk individuals to lung cancer by DNA polymorphisms of the cytochrome P450IA1 gene. FEBS Lett. 1990;263:131-3.

21. Pavanello S, Clonfero E. Biological indicators of genotoxic risk and metabolic polymorphisms. Mutat Res. 2000;463:285-308.

22. Sachse C, Bhambra U, Smith G, et al. Polymorphisms in the cytochrome P450 CYP1A2 gene (CYP1A2) in colorectal cancer patients and controls: allele frequencies, linkage disequilibrium and influence on caffeine metabolism. Br J Clin Pharmacol. 2003;55:68-76.

23. Jiang Z, Dragin N, Jorge-Nebert LF, et al. Search for an association between the human CYP1A2 genotype and CYP1A2 metabolic phenotype. Pharmacogenet Genomics. 2006;16:359-67.

24. Moonen H, Engels L, Kleinjans J, Kok T. The CYP1A2-164A$>$ C polymorphism $(\mathrm{CYP} 1 \mathrm{~A} 2 * 1 \mathrm{~F})$ is associated with the risk for colorectal adenomas in humans. Cancer Lett. 2005;229:25-31.

25. Le Marchand L, Donlon T, Seifried A, Wilkens LR. Red meat intake, CYP2E1 genetic polymorphisms, and colorectal cancer risk. Cancer Epidemiol Biomarkers Prev. 2002;11:1019-24.

26. Giannini E, Fasoli A, Botta F, et al. Helicobacter pylori infection is associated with greater impairment of cytochrome P-450 liver metabolic activity in anti-HCV positive cirrhotic patients. Dig Dis Sci. 2003;48:802-8.

27. Lauren P. The two histological main types of gastric carcinoma: diffuse and so-called intestinal-type carcinoma. An attempt at a histo-clinical classification. Acta Pathol Microbiol Scand. 1965;64:31-49.

28. Miwa H, Ghoshal UC, Gonlachanvit S, et al. Asian consensus report on functional dyspepsia. J Neurogastroenterol Motil 2012;18:150-168.

29. Ghoshal UC, Ghosh TK, Ghoshal U, et al. In-house rapid urease test kit and commercial kit: which is better? Indian J Gastroenterol. 1999; 18:183.
30. Hayashi S, Watanabe J, Nakachi K, Kawajiri K. Genetic linkage of lung cancer-associated MspI polymorphisms with amino acid replacement in the heme binding region of the human cytochrome P450IA1 gene. J Biochem (Tokyo). 1991;110:407-11.

31. El-Omar EM, Carrington M, Chow WH, et al. Interleukin-1 polymorphisms associated with increased risk of gastric cancer. Nature (Lond). 2000;404:398-402.

32. Figueiredo C, Machado JC, Pharoah P, et al. Helicobacter pylori and interleukin 1 genotyping: an opportunity to identify high-risk individuals for gastric carcinoma. J Natl Cancer Inst. 2002;94: 1680-7.

33. Belitsky GA, Yakubovskaya MG. Genetic polymorphism and variability of chemical carcinogenesis. Biochemistry (Mosc). 2008;73:543-54.

34. Malik MA, Upadhyay R, Mittal RD, Zargar SA, Mittal B. Association of xenobiotic metabolizing enzymes genetic polymorphisms with esophageal cancer in Kashmir Valley and influence of environmental factors. Nutr Cancer 2010;62:734-42.

35. Kamataki T, Fujita K, Nakayama K, et al. Role of human cytochrome P450 (CYP) in the metabolic activation of nitrosamine derivatives: application of genetically engineered Salmonella expressing human CYP. Drug Metab Rev. 2002;34:667-76.

36. Guo R, Guo X. Quantitative assessment of the associations between CYP1A1 polymorphisms and gastric cancer risk Tumour Biol. 2012;33(4):1125-32.

37. Jain M, Kumar S, Ghoshal UC, Mittal B. CYP1A1 Msp1 T/C polymorphism in esophageal cancer: no association and risk modulation. Oncol Res. 2007;16:437-43.

38. Agudo A, Sala N, Pera G, et al. Polymorphisms in metabolic genes related to tobacco smoke and the risk of gastric cancer in the European prospective investigation into cancer and nutrition. Cancer Epidemiol Biomarkers Prev. 2006;15:2427-34.

39. Tripathi S, Ghoshal U, Mittal B, et al. Glutathione-S-transferase enzyme activity and Helicobacter pylori: does association with GST polymorphisms explain the Indian enigma of gastric cancer? J Gastroenterol Hepatol. 2008;23:A118.

40. Hayes JD, Pulford DJ. The glutathione $S$-transferase supergene family: regulation of GST and the contribution of the isoenzymes to cancer chemoprotection and drug resistance. Crit Rev Biochem Mol Biol. 1995;30:445-600.

41. Verhulst ML, van Oijen AH, Roelofs HM, Peters WH, Jansen JB. Antral glutathione concentration and glutathione $S$-transferase activity in patients with and without Helicobacter pylori. Dig Dis Sci. 2000;45:629-32.

42. Tahara E. Genetic pathways of two types of gastric cancer. IARC Sci Publ. 2004;157:327-49.

43. Tripathi S, Ghoshal U, Ghoshal UC, et al. Gastric carcinogenesis: possible role of polymorphisms of GSTM1, GSTT1, and GSTP1 genes. Scand J Gastroenterol. 2008;43:431-9. 